\title{
Audit Risk Assessment Model
}

Submitted 03/01/19, 1st revision 29/02/19, 2nd rervision 25/04/19, accepted 25/05/19

\section{Arzhenovskiy S.V. ${ }^{1}$, Bakhteev A.V. ${ }^{2}$, Sinyavskaya T.G. ${ }^{3}$, Hahonova N.N. ${ }^{4}$}

\begin{abstract}
:
Purpose: The purpose of this study is the development of an audit risk model based on the decomposition of classical Audit Risk Model (ARM) with the addition of elements to assess the risks associated with various aspects of the task.

Design/Methodology/Approach: The classical ARM is the basis of our model. The factors of the first and second order in the proposed model are the same as in the classical ARM, namely, the risk of significant distortion and the risk of non-detection. The risk of material misstatement is disaggregated into inherent and control risks. We included in the list of second-order factors that affect the value of risk of significant distortion, the risk of material misstatement of financial statements due to unfair acts.
\end{abstract}

Findings: The paper contains the classic ARM's development analysis and the current researches in audit risk modeling review. We formulated the requirements to desired ARM's characteristics based on analysis we made. The ARM modification by classical conceptual model decomposition to the level of simple binary statements is presented. We describe the main structural elements of the developed model and their interrelations.

Practical Implications. The presented disaggregated ARM can be used as a methodological basis for assessing audit risk in the course of fulfilling assignments for the audit of financial statements.

Originality/Value: The classical ARM author's modification has been developed with the aim to its adapting to a practical risk assessment through logical-probabilistic modeling.

Keywords: Audit risk model, risk of material misstatement, risk of significant distortion, risk assessment, logical-probabilistic modeling.

JEL Code: C69, D81, M42.

Paper Type: Research article in Special Issue dedicated to Russian Economy.

Section 2: Banking \& Finance.

\footnotetext{
${ }^{1}$ Doctor of Science (Economics), Professor, Department of Statistics, Econometrics and Risk Assessment, Rostov State University of Economics, Rostov-on-Don, sarzhenov@gmail.com ${ }^{2}$ Candidate of Science (Economics), Associate Professor, Department of Business Analysis and Forecasting, Rostov State University of Economics, Rostov-on-Don a_bakhteev@mail.ru ${ }^{3}$ Candidate of Science (Economics), Associate Professor, Department of Statistics, Econometrics and Risk Assessment, Rostov State University of Economics, Rostov-on-Don, sin-ta@yandex.ru

${ }^{4}$ Doctor of Science (Economics), Professor, Department of Accounting, Rostov State University of Economics, Rostov-on-Don, $\underline{n \_k h a k h o n o v a @ b k . r u}$
} 


\section{Acknowledgement:}

The reported study was funded by RFBR according to the research project № 19-01000635 «Development of risk assessing concept of financial report falsification in the audit process on the bases of behavioral models».

\section{Introduction}

It is well known that risk is the most important backbone category, in auditing models. Significance is undeniable for audit theory, as well as its methodology and practice. In the works of the founders of modern audit (Dicksee, 1904; Montgomery, 1912; Limperg, 1926), dated the first two decades of the 20th century, the risk associated with the performance of an audit task is considered as an inevitable consequence of economic development accompanied by the development of corporations, an increase in the scale of their activities, the number of transactions, the emergence and rapid growth of absentee property and other similar processes. The auditors' response aimed at reducing the degree of uncertainty associated with the expression in more complicated external conditions of the opinion on the reliability of the audited financial statements was the use of selective testing carried out under the condition of having a proper internal control system ${ }^{5}$ from the client.

\section{Literature Review}

The idea of the inevitability of audit risk in the context of achieving a balance between the benefits associated with its presence and the costs, expressed in Dicksee (1904), developed in Montgomery (1912), Limperg (1926) and Mautz \& Sharaf (1961). This, in turn, initiated systematic scientific research aimed at understanding the essence, structure and key characteristics of the risks associated with the implementation of the professional function of the auditor both within the framework of a specific task and in the context of auditing in general. Studies in this area are conducted by scientists and audit practitioners from the mid-20th century.

The first and, undoubtedly, significant result of these studies was the emergence of the notion of audit risk and its conceptual model ARM (Audit Risk Model), describing its components and structure. These elements of the risk concept in the audit formed the basis of SAP No. $54^{6}$ introduced in the audit practice in the US in

\footnotetext{
${ }^{5}$ The term "proper system of internal control" was formulated by L.R. Dicksee taking into account the corporate governance practice that was being developed at that time. In the original language, this term writes like "proper system of internal check" and represents an element different from the modern concept of system of internal control (SIC) not only in terms of terminology, but also in its essential meaning. In the early twentieth century in the practice of company management there was no holistic concept of internal control, and there were only individual elements of the SIC in its current understanding. An example is the internal customer verification system (note by the authors).

${ }^{6}$ Issued CAP AICPA in November 1972 Statement on Auditing Procedure No. 54 Auditor's study and evaluation of internal control, in which for the first time the concept of audit risk,
} 
1972. The conceptual model of audit risk from SAP No. 54 is usually called classical, or traditional. Till present, many scientists and practitioners in the audit field (Mock \&Vertinksiy, 1985; Shibano, 1990; Haskins \& Dirsmith, 1993; Karagiorgos et al., 2007; Maximova \& Yakimova, 2013; Fortvingler \& Szívós, 2016) are building their studies of audit risk, based on this conceptual model. At the same time, with the advent of the ARM in audit theory, it has become clear that the basic structure of the conceptual model, contained in professional auditor standards, has a very limited range of applications. According to many researchers, the main condition for its effective application is the detailed and structured elements of the model to adapt the specific assessing methods of various risks for practice (RupeikaApoga et al., 2018). As a result, after the adoption of SAP No. 54 the modifications of the ARM obtained by applying the decomposition method began to appear in studies on the assessment of audit risk with sufficient regularity (Polyakova et al., 2019).

The result of one of these studies started in the late 1980's a group of American practitioners, became the model obtained as a result of decomposition of ARM, presented in (Srivastava \& Shafer, 2008). In his study authors undertook the attempt to create an audit risk assessment tool applicable in the auditing practice. They conclude that ARM, which is based on the requirements of the generally accepted auditing standardization systems, is too simplistic to present the audit risk structure in order to be used when creating an algorithm for assessing risks during the execution of specific tasks. The main reason limiting the practical application of traditional ARM, the authors call the model's insensitivity to risk assessment at the level of prerequisites for account balances, turnover and disclosure. As a result, they proposed a comprehensive model of audit risk, which included factors used in the traditional model, but evaluated at the assertion levels, accounts and audited statements as a whole. In addition, the proposed model included factors that allow considering of the risk associated with the analytical procedures performed while evaluating audit evidence at various levels. The proposed risk assessment model structure allowed the authors to use the trust function tool in auditor risk assessment.

The participants of another study, the results of which are described in (Beattie et al., 2005), came to the conclusion that the threats of independence arising from the fulfillment of tasks involving confidence, the threats of independence associated with pressure on the auditor, generate a factor that can be regarded as an independent component of the audit risk. Nevertheless, in conventional models, the threat to independence is not considered as a factor that influences the audit risk assessment. Therefore, authors (Beattie et al., 2005) propose to improve the existing ARM by including in it a factor called "within-firm risk".

its components and their interconnection was introduced, i.e. the world's first conceptual model of audit risk (further ARM) were structured (note by the authors). 
A team of German scientists conducted a study on the risk of quality assurance, the results of which were reported at the 16th annual World Symposium held in Argentina in 2006 (Schulze et al., 2006). The need for this study was due to the position of the authors, according to which such an element of ARM as the risk of non-detection does not provide sufficient opportunities for assessing audit risk in practice. As a result, the authors proposed to replace the risk of non-detection in the classical ARM model by the quality assurance risk, - an element having a complex structure. According to some authors the assessing of the quality assurance risk should be based on such factors as the inherent risk, resulting in an error, the risk of self-control, the risk associated with the imperfections of the SIC, the risk associated with the auditors' characteristics and the risk related to the professional competence of the auditor (Schulze et al., 2006).

In a study made by Iranian scientists (Hajiha, 2011) and published in 2011, they propose an audit risk model where ARM decomposition is carried out to adapt the conceptual model to its practical application audit risk assessement. Authors' decomposition uses the traditional ARM model factors without changes as elements of the first level of the model. The feature of the proposed variant of decomposition is the second level of the basic elements of the model risk factors disaggregation. Such a transformation of the model allowed the authors to adapt it for a decision tree creation, which is necessary for fuzzy logic techniques applying to risk assessment procedures in the course of the financial statement audit task. A similar approach was used in later studies (Sharma \& Panigrahi, 2015; Vasilenko, 2015).

Fraudulent data from financial statements is another practical and, as a consequence, a theoretical problem, necessitating the modification of ARM. It is well known that fraud is one of the key factors destabilizing world economic development. Despite this, the generally systems for standardizing audit activities, setting the auditor's responsibility to assess the risk of material misstatement of audited accounts due to both error and intentional fraud, does not provide a setting that allows for the interconnection of conceptual ARMs and FTTs ${ }^{7}$ in the course of the task. That is why many studies, started back in the 1990's, aimed at improving the ARM in order to adapt it to procedures for assessing the risk of intentional misstatement of financial statements. Studies (Zimbelman, 1997; Wilks \& Zimbelman, 2004; Srivastava et al., 2009; Favere-Marchesi, 2013), conducted in this direction, have received the most widespread fame. The various modifications of ARM resulting from the inclusion of the risk of material misstatement due to fraud in the structure of ARM and its decomposition into significant factors have become significant results achieved by the researchers of this group.

\footnotetext{
${ }^{7}$ The acronym FTT stands for Fraud Triangle Theory, which underlies the methodological approach to identifying and assessing the risk of material misstatement of financial statements due to fraudulent acts (note by the authors).
} 
The above examples characterize only the main directions of research aimed at improving the structure of ARM. However, it should be noted, that this is not an exhaustive list of currently completed and still ongoing scientific and practical research in this area.

\section{Results}

The above review allow us to systematize the results of research analysis in the field of improvement of ARM as follows:

$\checkmark$ First, all researchers view ARM as a conceptual model demonstrating a methodological approach to structuring audit risk.

$\checkmark$ Second, the practical application of ARM requires the adaptation of its elements to the specifics of the methodological tool used in the risk assessment during the audit.

$\checkmark$ Third, the universal way to adapt the conceptual ARM to the features of the risk assessment method used, is the decomposition adoption.

$\checkmark$ Fourth, it should be noted that most of the ARM decomposition studies are aimed at expanding the capabilities of the classical model by including ne factors. These factors allow to consider the influence of the internal environment of the audit company, the human reason, the quality of the audit, specific risk factors (the risk of fraud; the risk associated with the location of the auditor; the risk associated with the specific activities of the client in the audit, etc.).

Thus, the results of the overwhelming majority of the described and other now known studies show that all researchers are supplemented the components triad of the classical model of audit risk by factors that go beyond this model. We beleive that this is a clear confirmation that the current realities of the audit practice of the risks assessement are associated with the task require to expand the set of factors that affect the outcome of the audit.

The purpose of this study is the development of an audit risk model based on the decomposition of the classical ARM with the addition of elements to assess the risks associated with various aspects of the task. The desired model should be adapted to the use of the logical-probabilistic (further LV) method. In this regard, we formulated the basic requirements for the properties of the desired audit risk model as follows:

I. The ability to assess risks at all levels of audited information, namely, at the financial statement level as a whole and at the assertion level for classes of transactions, account balances.

II. The ability to take into account the impact on the task outcome of factors associated with the risk of deliberate distortion of audited statements.

III. The ability to take into account factors that affect the quality of the auditor's judgment (professionalism, independence, etc.). 
IV. The ability to assess permanently the state of the internal environment of the auditing company.

V. The ability to formulate, within the framework of the model, a description of the assessed risks based on simple statements that can be reduced to a binary form.

In the context of the formulated conditions, we developed a model for assessing audit risk, the scheme of which is shown in Figure 1. Classical ARM, introduced in the audit practice in 1972, is the basis of the model. Therefore, the factors of the first and second order in the proposed model are the same as in the classical ARM, namely, the risk of significant distortion (RMM) and the risk of non-detection (DR). The risk of material misstatement is disaggregated into inherent (IR) and control (CR) risks. In addition, we included in the list of second-order factors that affect the value of RMM, the risk of deliberate distortion of audited financial statements, better known as the risk of material misstatement of financial statements due to unfair acts (FR). This decision is due to the fact that the findings of the numerous studies carried out in the field of FR over the past several decades (Knapp Knapp, 2001; Shelton et al., 2001), as noted above, confirm the need to take this factor into account when assessing RMM, while the main methodological gap in the generally accepted systems standardization of audit activity is the absence of a model that allows to integrate FR into the conceptual model of audit risk (ARM).

Figure 1. ARM decomposition into a type applicable for LP modeling.

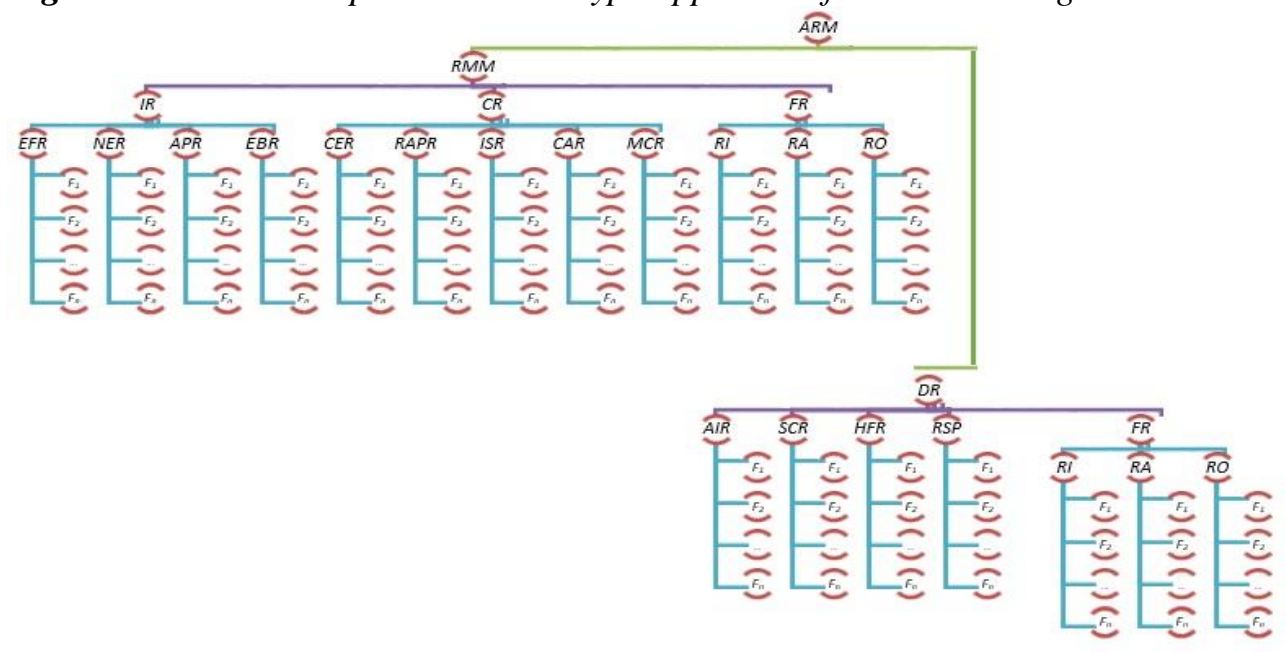

Another innovation of the proposed model is its disaggregation into the factors of lower orders, which allow constructing a decision tree for the audit risk assessement. So, in our opinion, third-order factors that affect the inherent risk assessment (IR) are: the risk associated with external factors affecting the organization's performance (EFR); the risk associated with the nature of the client's audit (NER); the risk associated with the change and application of accounting policies (APR); business risks of the organization associated with its objectives and strategy (EBR). 
In turn, each of the enumerated factors is decomposed into a number of elements (fourth-order factors), which are specific conditions for the audit client, on the basis of which a direct estimate of the risk can be made. As an example of a fourth-order factor, one can cite the auditor's assessment of the level of the industry's crisis, in which the client carries out his operational activities. The probability of the occurrence of an adverse event related to the inherent risk factors necessary for the construction of the LP-model should be evaluated on the basis of criteria that, in our opinion, can be used:

$\checkmark$ The level at which the factor under consideration affects the risk of material misstatement. It seems appropriate to distinguish two levels: a) the level of audited accounts as a whole, and b) the level of prerequisites for balances on accounts, groups of similar transactions, disclosure cases.

$\checkmark$ Materiality of the influence exerted by the factor on the value of RMM.

In the set of third-order factors that affect the control risk (CR), we proposed to include: the risk associated with the company's control environment (CER); the risk associated with the client's risk assessment process (RAPR); the risk of an information system related to the preparation of financial statements, business processes and information interaction (ISR); the risk of control actions related to the conducted audit (CAR); the risk of monitoring control tools (MCR). Fourth order factors influencing the assessment of $\mathrm{CR}$ are the characteristics of individual elements of the client's internal control system (SIC), which allow identifying specific risks. The evaluation of these elements is based on the following criteria:

$\checkmark$ The design of a specific element of SIC in the context of its compliance with the universal (requirements of regulatory legal acts) or intercorporate (goals and / or regulations for the introduction of an appropriate component of SIC) compliance.

$\checkmark$ The functioning of the SIC element under consideration in the period covered by the audited financial statements.

The structuring of the fraud risk with audited reporting (FR) is implemented in the proposed model in the context of the triangle of fraud theory (FTT). The FTT foundations of are set forth in (Sutherland, 1983; Cressey, 1954) and are used as the basis for generally accepted systems for standardizing auditing. Therefore, thirdorder factors are identified: the risk associated with the existence of incentives and (or) pressure (RI); the risk associated with the existence of opportunities for fraud (RA); the risk associated with the possibility of justification (rationalization) of fraud (RO).

Inclusion of FR element in the structure of the proposed model allows, in our opinion, to formalize the RMM assessment process not only due to errors, but also in the context of conscious manipulation of accounting data. Elements of the lowest order, related to the factor FR, are variables that determine the presence of 
incentives, opportunities and excuses (concealment) of manipulations with the audited reporting of the client. The impact of these factors on the RMM is assessed from the level (reporting as a whole or account balance, a group of similar transactions or disclosure cases).

A similar purpose, structure, and order of factor evaluation has an element FR in another part of the ARM that describes an algorithm for estimating the risk of nondetection (DR). FR refers to the risk of dishonesty by the auditor, which is a distinctive feature in the context of disaggregation of the risk of non-detection. In addition, third-order factors, to which the risk of non-detection is disaggregated, are: internal audit company risk (AIR); risk of the auditor's self-control (SCR); the risk associated with the human factor of the auditor (HFR); the risk that special procedures planned for fraud detection failed (RSP).

The criteria (in the context of which the probability of risk event occurrence is performed) used in the construction of the LP-model, are:

$\checkmark$ The level at which the consideration factor influences on the risk of nondetection. Similarly, with IR, there are: a) the level of the audited reporting as a whole, and b) the level of prerequisites for account balances, groups of similar transactions, disclosure cases.

$\checkmark$ Materiality of the influence exerted by the factor on the magnitude of the non-detection risk.

In our opinion, the optimally formulated criteria for selecting methodological tools for risk assessment during an audit can be implemented through the application of the logical-probabilistic method. The basis of the LP approach is the event-logic scheme. The essence of the LP approach is a sequential implementation of the algorithm, consisting of the steps is shown in Figure 2.

1. At the stage of formulation of the problem in a structurally logical form, a list of risk factors are determined. They can be represented as binary events of the form $\tilde{x}_{i}=\left\{x_{i}, \bar{x}_{i}\right\}, i=1, \ldots, h$, where $\bar{x}_{i}$ - the opposite for $x_{i}$ event, $h-$ number of such factors forming a set of $X$. It is assumed to be possible for each factor to set the probability of its realization $p_{i}$ (or unrealization $\left.q_{i}=1-p_{i}\right)$. Subsequently, risk factors must be aggregated into integral implementation functions $y$ for each risk element that form a set of $Y$. The content and logical conditions of the functions must be defined. At the same stage, a verbal and graphic description of the sets $X$ and $Y$ is given. They are formed a scheme of functional integrity for the risk situation $G(X, Y)$. Then the output logic functions $Y_{F}\left(y_{j}\right), j=1, \ldots, n$ are constructed for the circuit. That is, the formulas for realizing the main risk situations are set - the logical criteria of functioning. 
Figure 2. Sequence of implementation of the LP-approach.

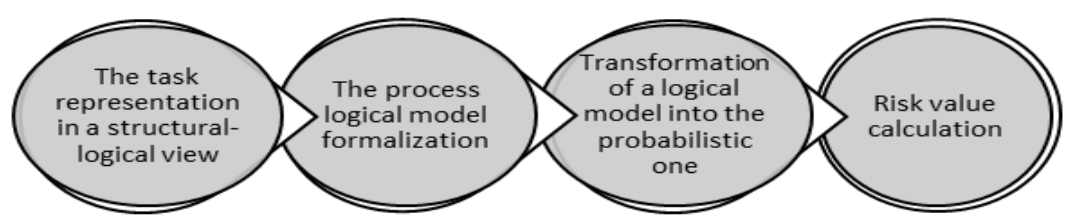

2. At the stage of constructing a logical model, the function of working capacity for the entire process $Y_{F}\left(\tilde{x}_{i}\right), i=1, \ldots, h$ is determined by transforming the logical criteria of functioning. The result is a logical function that describes all possible outputs of $F$ for various combinations of input factors $\tilde{x}_{i}, i=1, \ldots, h$.

3. At the stage of constructing a probabilistic model, the function of working capacity is transformed into a probability function of the form $P_{F}\left(p_{i}, q_{i}\right), i=1, \ldots, h$. The resulting polynomial allows you to perform risk calculation for specific embodiments of binary events.

4. The risk value is calculated using the probability function for given probabilities $p_{i}$. The quantitative risk assessment is calculated for the process as a whole.

The system of factors, which describes the possible presence of unscrupulous actions, is given in Figure 1 and includes 19 parameter events, each of which includes event-gradations that constitute a number of nonspecific events. Let $Y$ be a binary variable corresponding to a situation of absence (value 0 ) or the existence of a material misstatement of financial statements as a result of unfair actions (value 1). The values of the factors are formed according to the following classes (Figure 1): $X_{1}=\mathrm{EFR}, X_{2}=\mathrm{NER}, \ldots, X_{18}=\mathrm{RA}, X_{19}=\mathrm{RO}$.

We follow the logic from (Solozhentsev, 2009). With certain probability, these events lead to a material misstatement of financial statements as a result of unfair acts. Distortion then occurs $(Y=1)$ when any one, two, several or all eventparameters occur.

The logical model of the risk of significant distortion will be written in the form $Y=X_{1} \vee X_{2} \vee \ldots \vee X_{19}$

Transforming into the orthogonal form, we obtain: 
$Y=X_{1} \vee X_{2} \overline{X_{1}} \vee X_{3} \overline{X_{2} X_{1}} \vee \cdots$

The corresponding probabilistic risk model is:

$P=p_{1}+p_{2} q_{1}+p_{3} q_{1} q_{2}+\ldots$

where $p_{i}$ - probability of distortion of reporting for event-parameters, $q_{i}-$ probability of reliability of reporting, $q_{i}=1-p_{i}$.

Probabilities for event-parameters are calculated on the basis of probabilities for gradation events. Denote the last $p_{i j}, i=1, \ldots, n, j=1, \ldots, n_{j}$, here the number of parameters $n=19, n_{j}$ - the number of gradations in each $j$-th group. Suppose that an acceptable risk level for an audit is a risk with probability $P_{d}$, and a risk is calculated for $N$ audited organizations $P_{k}, k=1, \ldots, N$. A significant distortion of the financial statements due to fraud occurs when $P_{k}>P_{d}$. The training of the logical-probabilistic model is carried out according to statistical data and consists in the calculation of $p_{i j}, P_{d}, P_{k}$. All $N$ organizations fall into one of four groups: $N_{g g}-$ conscientious in the model and statistics, $N_{g b}$ - conscientious in the model and unfair in statistics, $N_{b g}$ - unscrupulous in the model and conscientious in statistics, $N_{b b}$ - unscrupulous in the model and statistics.

The logical-probabilistic model for risk assessment in audit is formulated as follows. Input data: there is a statistical database of $N$ organizations, of which a part $N_{g}$ has no material misstatement of financial statements due to fraud, and some $N_{b}$ have, and for each organization the model (1) is valid, so for all $N$ organizations we obtain a system of equations of the form (1). Output result: to determine the probability $p_{i j}$, $i=1, \ldots, n, j=1, \ldots, n_{j}$ and the permissible risk $P_{d}$, that divides organizations into conscientious and unfair, so as to maximize the number of organizations with the correct classification

$L=N_{g g}+N_{b b} \rightarrow \max$

The limitations of the model are requirements: a) $0<p_{i j}<1, i=1, \ldots, n, j=1, \ldots, n_{j}$, b) the average risks in the model (1) and according to statistical data should be the same, c) the risk $P_{d}$ is determined taking into account the equality of errors in the recognition of bona fide and unscrupulous organizations. Errors in the recognition of the model are determined for bona fide organizations as $E_{g}=N_{g b} / N_{g}$ and for unscrupulous ones $E_{b}=N_{b g} / N_{b}$. The average error for all organizations is: $E=(N-L) / N$. 


\section{Conclusion}

The paper presents the developed audit risk model based on the decomposition of classical ARM with the inclusion in it of additional elements, allowing assessing the risks associated with various aspects of the task. The model is adapted to the logicalprobabilistic method usage. The basic requirements describing the properties required for the desired model of the audit risk are formulated.

The presented disaggregated ARM can be used as a methodological basis for assessing audit risk in the course of fulfilling assignments for the audit of financial statements. It should be noted that the scope of the proposed model is not limited only to audit tasks. It can be used to assess the risk associated with the performance of other tasks involving an expression of confidence.

Based on the ARM approach, a logical-probabilistic model is formulated to assess the risk in the audit. In our opinion, the application of the logical-probabilistic approach as a tool for risk assessment in the audit within the framework of ARM will improve the quality of audit judgments while reducing the labor budget.

\section{References:}

Beattie, V., Fearnley, S., Brandt, R. 2005. Auditor independence and audit risk: a reconceptualization. Journal of International Accounting Research, 4(1), 39-71.

Cressey, D.R. 1954. Differential association theory and compulsive crimes. Journal of Criminal Law and Criminology, 45(1), 29-40.

Dicksee, L.R. 1904. Auditing: Practical Manual for Auditors. 6th edn. Gee \& Company.

Favere-Marchesi, M. 2013. Effects of Decomposition and Categorization on Fraud-Risk Assessments. Auditing: Journal of Practice \& Theory, 32(4), 201-219.

Fortvingler, J., Szívós, L. 2016. Different Approaches to Fraud Risk Assessment and Their Implications on Audit Planning. Periodica Polytechnica Social and Management Sciences, 24(2), 102-112.

Hajiha, Z. 2011. Fuzzy audit risk modeling algorithm. Management Science Letters, 1, 235 246.

Haskins, M.E., Dirsmith, M.W. 1993. Control and Inherent Risk Assessments in Client Engagements: Examination of Their Interdependencies. Journal of Accounting and Public Policy, 14, 63-83.

Karagiorgos, T., Drogalas, G.S., Pazarskis, M.D., Christodoulou, P.T. 2007. Internal auditing as main tool for efficient risk assessment, MIBES, 722-734.

Knapp, C.A., Knapp. M.C. 2001. Effects of experience and explicit fraud risk assessment in detecting fraud with analytical procedures. Accounting, Organizations and Society, 26, 25-37.

Mautz, R.K., Sharaf, H. 1961. Philosophy of Auditing. Sarasota, Fl.: American Accounting Association.

Maximova, G.V., Yakimova, V.A. 2013. Audit risk and sufficiency of evidence. International accounting, 28, 22-34. 
Mock, T.J., Vertinksiy, I. 1985. CGA Research Monograph Number 10: Risk Assessment in Accounting and Auditing: A Research Report. Canadian Certified General Accountants' Research Foundation. Vancouver, British Columbia.

Polyakova, A.G., Loginov, M.P., Serebrennikova, A.I. \& Thalassinos, E.I. 2019. Design of a Socio-Economic Processes Monitoring System Based on Network Analysis and Big Data. International Journal of Economics \& Business Administration, 7(1), 130-139.

Rupeika-Apoga, R., Zaidi, H.S., Thalassinos, E.Y. \& Thalassinos, I.E. 2018. Bank Stability: The Case of Nordic and Non-Nordic Banks in Latvia. International Journal of Economics \& Business Administration, 6(2), 39-55.

Sharma, A., Panigrahi, P.K. 2012. Review of Financial Accounting Fraud Detection based on Data Mining Techniques. International Journal of Computer Applications, 39(1), 3747.

Shelton, S.W., Whittington, O.R., Landsittel, D. 2001. Auditing firms' fraud risk assessment practices. Accounting Horizons, 15(1), 19-33.

Shibano, T. 1990. Assessing audit risk from errors and irregularities. Journal of Accounting Research, 28, 110-140.

Schulze, H., Albersmeier, F., Spiller, A. 2006. Checklist Governance: Risk-oriented audits to improve the quality of certification standards in food sector. In: IAMA Conference, Buenos Aires, Argentina: 16th Annual World Forum and Symposium «Agribusiness, Food, Health, and Nutrition».

Solozhentsev, E.D. 2009. Risk management and efficiency in the economy: Logicalprobabilistic approach. SPb., Publishing House SPbGU.

Srivastava, R.P., Mock, T.J., Turner, J.L. 2009. Bayesian Fraud Risk Formula for Financial Statement Audits. Abacus, 45(1), 66-87.

Srivastava, R.P., Shafer, G.R. 2008. Belief-function formulas for audit risk. Classic Works of Dempster-Shafer Theory of Belief Functions. Springer-Verlag Berlin Heidelberg.

Sutherland, E.H. 1983. White Collar Crime. Westport, Conn., Greenwood Press.

Vasilenko, A.A. 2015. Methodological aspects of application in audit of the prerequisites of financial statements. Rostov-on-Don, Science-Spectrum.

Wilks, T.J., Zimbelman, M.F. 2004. Decomposition of fraud-risk assessments and auditors' sensitivity to fraud cues. Contemporary Accounting Research, 21(3), 719-745.

Zimbelman, M.F. 1997. Effects of SAS № 82 on Auditors’ Attention to Fraud Risk Factors and Audit Planning Decisions. Journal of Accounting Research, 35, 75-97. 